\title{
Genetic Genealogy as an Emerging Research Branch of Human Ancestry and Origin (Review of Curricula and Other Learning Sources)
}

\author{
Lolita Nikolova* \\ Ancestry ProGenealogists, Salt Lake City, Utah, USA
}

*Corresponding Authors: Lolita Nikolova, Ancestry ProGenealogists, Salt Lake City, Utah, USA

\begin{abstract}
Genetic genealogy is an emerging branch of the complex 21st-century science of human ancestry and origin. It features intersecting research interests, including traditional genealogy, population genetics, physical anthropology, cultural anthropology, history, sociology, health sciences, and other fields in the humanities. Study of this branch points out the absence of traditions, including genetic genealogy, in the academic campus curricula. At the same time, an integral component of genetic genealogy is population genetics, which is a basic academic subject.

This research review assesses three types of curricula: curricula for genetic genealogy courses, curricula for population genetics courses, and curricula for general (integrative) genealogy. The description of the second and third types focuses on how they relate to the curriculum for genetic genealogy courses. In addition, many other resources for curricula are analyzed, since numerous publications and websites offer important learning tools and embed elements of academic curricula.
\end{abstract}

Keywords: Genetic Genealogy, Curriculum, Genealogy, Population Genetics, Anthropology

\section{SetTing}

Genetic genealogy is an emerging branch of the complex 21 st-century science of human ancestry and origin (Nikolova, 2017). It features intersecting research interests, including traditional genealogy, population genetics, physical anthropology, cultural anthropology, history, sociology, health sciences, and other fields in the humanities. Study of this branch points out the absence of traditions, including genetic genealogy, in the academic curricula. At the same time, an integral component of genetic genealogy is population genetics, which is a basic academic subject.

This research review assesses three types of curricula: curricula for genetic genealogy courses, curricula for population genetics courses, and curricula for general (integrative) genealogy. The description of the second and third types focuses on how they relate to the curriculum for genetic genealogy courses. In addition, many other resources for curricula are analyzed, since numerous publications and websites offer important learning tools and embed elements of academic curricula.

The literature review in this chapter will answer the following questions:

- How do the curricula cover contemporary genetic genealogy research and its social applications?

- What other learning sources for genetic genealogy exist beyond courses?

- What is the place of genetic genealogy within the population genetics curricula and/or other learning sources?

- What is the place of genetic genealogy within the general genealogy curricula and/or other learning sources?

- What gaps will a new curriculum for a genetic genealogy course fill within academic settings?

The criteria of the critical approach in this literature review are based on the main standards elaborated for academic curricula and the main achievements in the curricula studies (see e.g. Kridel, 2010). 


\subsection{Curricula for Genetic Genealogy Courses}

Genetic genealogy is an emerging academic field. Examples for genetic genealogy courses are rare; most that do exist come from practitioners. They have a practical goal of assisting those researching family history to apply DNA results to family trees, or to assist in unknown bioparenting cases when adopted children search for their biological parents.

The National Genealogical Society (NGS) offers two fee-based courses on genetic genealogy (2017a, 2017b). They do not provide certificates since the society has no license for academic teaching. The online courses primarily seem to attempt to assist individuals interested in their origin based on the results of DNA tests. It is an innovative offering by the NGS, since it typical educational form is lectures and workshops at its annual national conferences.

The first course, organized into six modules, is on the basics of genetic genealogy (National Genealogical Society, 2017a). According to the syllabus, it includes an implicit curriculum focusing on DNA molecules, chromosomes, and markers; a Y-chromosome surname project; the mitochondrial DNA molecule; and inheritance of mtDNA. Specific objectives of the course are that students understand the structure of the DNA molecule as well as its organization, replication, and function. The course also attempts to teach students about human chromosomes and how the Y-chromosome is inherited. Other objectives are to help students recognize and become familiar with the two types of DNA markers used in genetic genealogy; learn the concepts of haplo types and haplo groups; examine a Y-chromosome surname project and evaluate the test results of the participants; and understand the structure of the mitochondrial DNA molecule, how it is inherited, and how it can be used in genealogy (Syllabus in National Genealogical Society, 2017a). The methodology of teaching is self-study, including self-tests.

The second course focuses on autosomal DNA, utilizing the concepts and techniques of genetic genealogy (National Genealogical Society, 2017b). The course material, organized into seven modules, is designed for intermediate-level students in genetic genealogy. Like the first course, it attempts to assist those interested in researching their origins. After the course, students should be able to understand how autosomal DNA (atDNA) and X-DNA are inherited, how DNA recombines, and how the use of at DNA test results in genealogy can identify likely common ancestors based on proposed genetic cousins. They also should understand how results from different companies can affect personal test results and know how to most effectively use these results along with more advanced tools for analyzing at DNA test results (spreadsheets, GEDmatch-featured tools, DNA ged com-featured tools, etc.).

The syllabus of the course is explicit and provides details about each module. The main value of the course curriculum is its well-defined framework for the proposed audience-individuals interested in their own origins. It also focuses on peculiarities in the results from DNA tests offered by different companies.

Many online websites offer assistance in understanding the results from specific companies-in particular, AncestryDNA, 23\&Me, and FamilyTreeDNA - or to study specific surnames (the socalled surnames project) in depth.

For instance, the beginner's guide to genetic genealogy complements the website on the common ancestry of the Wheaton/Wheadon family trees (Wheaton Surname Resources, 2013). Nineteen lessons were developed by practitioners in genetic genealogy. The subjects of the lessons are Y-DNA and at-DNA, origin, SNPs, mapping, differences between the results of the DNA test providers, etc.

The lessons clearly articulate the terminological and conceptual differences between AncestryDNA, $23 \& \mathrm{Me}$, and FamilyTreeDNA. For instance, the three companies use different names for origin: genetic ethnicity estimates (AncestryDNA), population finder (FamilyTreeDNA), and ancestry composition $(23 \& \mathrm{Me})$. The website also links to free articles written by genealogy experts and vivid case studies (Lesson 18, Exploring the Y Haplotree with a real-life example). Overall, the lessons represent research results in progress instead of a simplified framework of the thematic of genetic genealogy, and can be used as a reference guide in researching any ancestral origin.

McAllister (2016) offers an online course in genetic genealogy that has a broader goal of comparing genetic information in a global context. The course developed as a 15-week study of online texts (including links) with class discussions. It attempted to assist individuals to interpret their DNA test 
results from $23 \& \mathrm{Me}$. The website does not indicate whether this course had students, but the synthesis of key problems of genetic genealogy and the themes offered for class discussion form a model for the critical implementation of the material into a successful academic course. The debate over geneticists' conclusions on the basic topic of origin requires the students to be aware of different approaches and the various opinions that exist, thereby learning from different curriculum experiences. Accordingly, the critical use of the expert's knowledge stimulates the development of the academic curriculum for genetic genealogy, although B. F. McAllister's course shares the general challenge of the curricula offered for genetic genealogy - the absence of references to the basic literature used.

Coursera, one of the main avenues for mass communication related to education, does not include a course on genetic genealogy (Coursera, 2017). However, along with the aforementioned thematic courses offered by several not-for-profit organizations, learning courses are available from the companies that provide DNA kits (e.g. AncestryDNA, 23\&Me, FamilyTreeDNA, etc.), as well as on youtube.com and other social media. Genetic genealogy is also an issue in the social media-based annual conference of genealogical organizations.

The most noticeable common characteristic is the thematic approach of the courses on genetic genealogy (e.g., Genetic Genealogy 101, 2018; Genetic Genealogy Resources, 2018) or generally on genealogy (e.g., Courses for Success, 2018; Online Courses, 2018).

The general conclusion is that current courses on genetic genealogy do not include a complete multiperspective, interdisciplinary approach to genetic genealogy as an independent discipline. Most of the courses have a practical goal of assisting family history researchers in applying their DNA results to their family tree or for resolving adoption problems.

\subsection{Curricula for Population Genetics from the Perspective of Genetic Genealogy}

The foundation of genetic studies is crucial for the development of the subject of genetic genealogy. For this reason, it is important to outline the main achievements of genetic studies that have a direct impact on genetic genealogy.

Since the late $20^{\text {th }}$ century, the shift from classic to molecular genetics has completely changed the framework and content of population genetics studies and curricula. In his monograph, M. Hamilton (2009) included an alternative body of data to enrich the manner of teaching and learning population genetics. His assessment of the $20^{\text {th }}$-century framework is that population genetics was hypothesisrich but data-poor. The wealth of genomic data gathered in the late $20^{\text {th }}$ century in the fields of molecular biology, genomic data, and DNA sequencing had the opposite consequence for population genetics, making for a data-rich but hypothesis- meager discipline.

One key topic that combines gene history and genetic genealogyis the coalescent theory. The monograph of Hein et al. (2004) is considered the pioneer textbook approach to coalescent theory.

R. M. Kliman focuses on introducing students to stochastic processes. His reminder that while "genehistories are influenced by population histories, the time to the MRCA of a given gene clearly does not tell us when a population or species arose" (2001: 13) is crucial for genetic genealogy, especially after 2012, with the wider adoption of atDNA.

Simulation methods (Hoban et al., 2012; Kliman, 2001) are very important for population genetics. A detailed review by Hoban et al. (2012) includes a long list of software used in simulation studies of population genetics, as well as clustering problems that require simulation methods. At the same time, Kliman points out that "while simulation can provide insight into the often broad distribution of population histories under a given set of assumptions, the actual history, being analogous to a single iteration, cannot be inferred with much confidence. In fact, ignoring this point will lead to overconfidence in the placement in time of an MRCA." (2012: 14) Although genetic genealogy analyzes in-depth lineages, the methods of lineage generation can be tested against the gene generations in order to reconstruct population history as a history of individuals with specific places of origin.

In contrast to the specific field of genetic genealogy, population genetics studies are among the most popular academic disciplines. The theoretical literature on genetic curriculum (e.g., Murray-Nseula, 2011; Cheesman et al., 2007; McElhinny et al., 2014) stresses the following main characteristics: 
- The complex and abstract nature of many genetic concepts makes this subject challenging and difficult for teaching and learning.

- The genetic curriculum reflects conceptual complexity because of multi-level thinkingmolecular, cellular, organismal, and population levels, or micro (chromosomes, gametes), macro (organismal), and molecular (DNA, genes) levels.

- Genetics is a fast-paced field, especially because of the revolution in genomic studies, so the curriculum competes with informal sources of information regarding the newest discoveries.

- Typically, the genetic curricula reproduce the old instructional approach established in the 1940 s, the framework of which is the chronological order of discoveries and innovations. The call for genetic education reform refers to the integration of concepts, discussion of social issues, inquiry-based pedagogy, development of analytical skills and critical thinking, casebased teaching (CBT), etc.

- Genetics requires atypical methods of assessment, since solving problems presumes searching for more than one approach and memorization is a traditional study habit that is ineffective for genetics.

Genetic education is important for the genetic genealogy curriculum because it provides genetic literacy and methods of understanding DNA data. McElhinny et al. (2014: 448) refer to six core genetic concepts as the learning goals of genetic studies: DNA, Mendelian, gene expression, genes + environment, variation, and genes + society. Obviously, genetic studies provide only a general framework for developing core genetic literacy in genetic genealogy courses since the core concepts in genetic genealogy are not just DNA but y-DNA, mt-DNA, at-DNA, and an-DNA. In other words, despite having a common learning objective-the development of knowledge on basic genetic concepts - the modules on genetic literacy are specific for the different branches of integrative genetic studies.

The authors cited above studied 32 syllabi and 10 textbooks to reveal common themes and unique characteristics of U.S. genetic courses. Unfortunately, they limited the research to six core concepts selected by them, while in the era of open access and Internet sources, the syllabi are tools for instructional learning of the integrated concepts and their context, application, and dynamics within the studied subjects. Compartmentalizing topics complicates teaching and learning (Murray-Nseula, 2011).

Cheesman et al. (2007 with ref.) reported the results of 403 surveys about the biology department curriculum, which included genomic subjects. They reported that only a few changes were made in the last 17 years, after the published survey by Heppner and colleagues in 1990.

From a global perspective, the Australian project on genetics education in the 21st century from 2008 is interesting. Its goal was to develop an innovative curriculum on genetic education in science classes in western Australian secondary schools. The main targets of transformation were the typical, traditionally taught concepts like the simple Mendelian laws of inheritance. The model of multifactorial human conditions was proposed in order for the students to understand the interrelation between the genetic predisposition to the condition (case studies on asthma, diabetes, and celiac disease) and exposure to an environmental trigger before the emergence of symptoms of the condition (Dawsonet al., 2010).

A review of the available online syllabi of population genetics shows that the academic focus is on specific problems including human population genetics and heritability (e.g., NCSU, 2017). Interestingly, the University of North Carolina at Chapel Hill, a top doctoral educator in population genetics, has only one course on human genetics and genomics (one credit) (UNC, 2017). It also does not focus special attention on ancient population genetics, even though this is one of the most popular branches of population genetics today. The absence of in-depth academic education on genetic genealogy and ancient population genetics at the $\mathrm{PhD}$ level is probably one of the reasons the geneticists of the early $21^{\text {st }}$ century repeat in their conclusions the archaeological theories of the $20^{\text {th }}$ century, some of which are outdated. Accordingly, this review of curricula in population genetics also applies to the genetic genealogy curriculum, which must include development of a critical approach 
not only to genetic cousins, for instance, but also to the geneticists' theories of origin, especially if they overlap with outdated archaeological theories. Typical example is the attempt of rebirth of the M. Gimbutas' steppe invasion theory of Indo-Europeazation of Western Europe (see e.g., Haak et al., 2015; Cassidy et al., 2016), which has been critically analyzed for years as a theory of absurd even for the Balkans (Nikolova, 1999).

Last but not least, the National Science Foundation provided a grant in the early $21^{\text {st }}$ century to the Genetics and Genealogy working group at the Hutchins Center for African \& African American Research at Harvard University (with co-directors Henry Louis Gates Jr. and Evelynn M. Hammonds) to develop a curriculum on personalized genetics and genealogy. The goal was to incorporate genealogical study into the introductory biology course at Spelman College (National Science Foundation, 2017). The project embodies a new pedagogical model for combining personalization with a discovery-based approach in an interdisciplinary context, implemented in an environment featuring a black minority population. The learning tool is the personal DNA of the students. In fact, together with the innovative approach, the project reflects the undervaluation of genealogy as an important subject in classrooms from the elementary school level to the collegiate academic level. This undervaluation has created a huge gap in education and reveals the need to rediscover the importance of embedding personal case studies in the natural and social science curricula. Henry Louis Gates Jr. extended the Spelman College project by involving social media, as PBS initiated the TV series Find Your Roots(PBS, 2017). In the literature, the need for a curriculum on the genealogical perspective of social history had already been outlined in depth in the late $20^{\text {th }}$ century, and developed as an actual inquiry in the early $21^{\text {st }}$ century (see e.g. .Taylor \&Crandall, 1986; Jones, 2007).However, the burgeoning interest in DNA testing, especially after 2012, finally created a context for genealogy to become an integrative emerging science at a high academic level.

\section{CURRICUlum ReSourCeS FOR GeNeTIC Genealogy COURSES}

\subsection{Wiki and Case Studies in Genetic Genealogy}

The International Society of Genetic Genealogy's (2018) wiki is a basic professional source for genetic genealogy. It is a free website offering videos, webinars, and articles by experts that promote learning experiences and reflection on genetic studies. Genetic glossaries, genetic timelines, and indexes contribute to the website's usefulness. The material on the website can be used as a source for developing explicit curricula in genetic genealogy.

The Genetic Genealogist website, authored by B. Bettinger (2018), provides a list of lessonpresentations (basic, intermediate, and advanced courses) without published syllabi. B. Bettinger is the author of a highly popular monograph on DNA testing and genetic genealogy (2016), the content of which can be used as a basic textbook on genetic genealogy, along with his other book in collaboration with D. P. Wayne (Bettinger\& Wayne, 2016).

Public libraries also provide important resources that can fill academic gaps in genealogy education, including genetic genealogy. For instance, the Genealogy Division of the Indiana State Library has a special publication about genealogy resources for K-12 educators (Indiana State Library, 2006).

The National Center for Case Study Teaching in Science (2017) (NCCSTS) has a case study collection for faculty only, with teaching notes and answer keys for subscribers. For the time being, only one case refers to genetic genealogy-King Tut's Family Secrets (National Center for Case Study Teaching in Science, 2017). The case was elaborated in a PowerPoint presentation with 66 slides to assist a freshman biology lab course, but since it is an excellent case for genetic genealogy, it also can be used as a model for developing other case studies to include in an academic genetic genealogy course, even though the learning objectives would be different.

\subsection{Constitution of Genetic Genealogy as an Emerging Complex Interdisciplinary Science}

The expanded role of DNA in personal genealogy research has been stimulating population genetics studies, which in turn constitute genealogy as an emerging complex applied science. In particular, DNA methodology and technology has been constantly enriching the field with discoveries and innovations that immediately affect lineage research, especially in relation to ethnicity and origin. Consequently, the topic of genetic genealogy has been spreading widely in the network of academic journals, becoming an emerging complex interdisciplinary science (see, e.g. Larmuseau et al., 2013). 


\subsection{Innovations in Genetic Studies and Genetic Genealogy}

Genetic genealogy depends on the development of general genetic studies, so the literature review needs a brief clarification of the main tendencies in the recent advance of genetic studies based on their possible impact on genetic genealogy research. Since mutations present one of the main problems with using DNA for genealogy, all research in the field of microbiology that applies to the evolution of human civilization is important for keeping the theory of genetic genealogy updated. Genetic genealogists often do not know about research completed by geneticists who use the genealogical database and genealogical methods.

The most important factor is the advancement in genome sequences. The mitochondrial genome sequence was first introduced by the Cambridge Reference Sequence (1981), revised in 1998 (Andrews et al., 1999, cp. Behar et al., 2012). The rCambridge Reference Sequence is available online as Homo sapiens mitochondrion, complete genome (NCBI Reference Sequence: NC_012920.1) (NCBI, n.d.).

One example is a research project that attempted to develop a measurable methodology to study evolutionary fitness (Mostafavi et al., 2017) used a genealogical data bank. The authors tested whether the frequency of an allele (the gene variants) depends on age variations, accounting for variation in ancestry. They concluded that there was a connection between the delay in puberty timing and a longer parental life span, while the later age of first birth was associated with a longer maternal life span.

Another example is the current research on a glycan modification called N-glycolylated chondroitin sulfate (Gc-CS). Because of loss-of-function mutation, which occurred 2-3Mya in the hominin lineage, humans cannot biosynthesize Neu5Gc (Bergfeld et al., 2017). An open question for genetic genealogy is whether the Neu5Gc that humans can process through food has an impact on the reproductive functions of humans and DNA mutations.

One large group of research studies relates to diseases and genomic studies and may help explain different peculiarities in lineage history. In other words, they interrelate DNA, genealogy, and health/disease problems. The problem of the resistance to cancer in the way it is described by Klein (2015) is one interesting case in point. The author asks whether human genetic variation has an impacton cancer resistance. He provides an example with well-mapped Icelandic families, concluding that it is impossible to distinguish whether the families not affected by the disease were genetically resistant to cancer or that they avoided the disease purely by chance. In this case, it looks as though the author's theoretical framework is limited to non-contextual analysis of the genomic dependence of the humans, since the families categorized as being cancer-free "by chance" may have simply indicated "cancer-free" in an environmental, social, or cultural context.

The methodological aspects of the interrelation between genetic genealogy and genome studies is how geneticists use genealogical data in genome research. Some of the popular statistical methods come from the category of survival models in statistics, such as the Cox proportional hazard model, accelerated failure time model, etc. The genotype imputation attempts to predict the genotypes that a sample of individuals does not directly reveal (UK Biobank, 2015).

The scientific research on the transgenerational effects of genome instability (Kovalchuk\&Kovalchuk, 2010) are important for genetic genealogy. The studies include both research of the historical evolution of species and of different methods of genetic engineering (e.g. CRISPR) (see also, Herrera et al., 2016).The Encode Project Consortium (2012) has a special website where the results of the project research on DNA were summarized, together with regular updates (ENCODE, 2018).

Genetic genealogy may collaborate with general genetic studies to develop more precise hypotheses on the role of non-genetic inheritance in human diversity. The topic of non-genetically inherited traits is a special subject in the methods of building double pedigrees, both genetic and cultural. The cultural pedigree would describe "lineages" of segregating cultures "that sum up to the culture in which an individual is raised" (Danchin et al., 2013). This method in biological evolution studies can be directly applied to genetic genealogy, since building pedigrees of the cultural context of ancestors (through collateral data) may assist in explaining peculiarities of genetic inheritance.

Advancements in understanding genes are also very important for genetic genealogy. Scientists no longer recognize a gene as "a discrete and autonomous agent powerfully leading traits and 
developmental processes" since, in particular, "a very small percentage of the genome (less than $2 \%$ ) act according to the classical definition of the gene as a protein-coding sequence, but most of the nonprotein coding DNA in fact plays an important regulatory function" (Meloni, 2014). Accordingly, the genome is best described as a "vast reactive system...embedded in a complex regulatory network with distributed specificity" (Meloni, 2014). M. Meloni concludes that "an important part of this regulatory network is involved in responding to environmental signals, which can cover a very broad range of phenomena, from the cellular environment around the DNA, to the entire organism and, in the case of human beings, their social and cultural dynamics" (2014). Therefore, scientists no longer see the genes as "codes" in development, but as "catalysts" and "followers" rather than "leaders" in evolution (Meloni, 2014, and references cited there).

Haplogroups are a leading genetic genealogy attribution. Each haplogroup has different areas of distribution and different chronologies. To apply general knowledge to personalized history, actualized basic knowledge in phylotrees and on clades is a good place to start. A free website from the University of California-Berkeley provides a one-stop source for information on evolution (Understanding Evolution, n.d.).

\subsection{Studies on DNA and Ethnicity}

One of the main problems of genetic genealogy is origin, or "ethnicity."Thanks to advances in genomic studies, the different DNA tests provide their own conclusions about origins, and they could be similar or different. However, in all cases the goal is to determine origin dating back several thousand years. Using archaeological data about ancient populations could help articulate the hypotheses more thoroughly. However, autosomal DNA reflect deep ancient roots without providing haplogroups for comparison. The data from mtDNA are more promising.

Two reviews of literary works, provided by Evison $(2003,2014)$, contribute significantly to solving the problem of interaction between archaeology and genetics. The author embraces the huge region of Eurasia by chronologically following the advance of ancient DNA research and problems raised by the new data. He pays particular attention to the interrelation between the pre-DNA conclusions based on the blood groups as well as on the sensitivity of the ancient samples and risk of contamination. $\mathrm{He}$ supports the models of demic diffusions in Europe from Anatolia and also points to the fact that the so-called linguistic groups correlate with paleographical peculiarities, so the genetic study may reflect not an ancient linguistic group, but groups divided by natural geographic barriers.

In results reported in 2006, Bosh et al. did not make any significant differentiation between their samples from the Balkans regarding the variety of yDNA and mtDNA. The samples include Albanians, Romanians, Macedonians, Greeks, and five Aromun populations. The authors mentioned only peculiarities about Aromun populations, inferring possible correlation between the genetic data and the ancient origin of Aromuns, based presumably on their Romance-rooted language. The article does not include samples from contemporary Bulgaria, but Macedonians are historically-rooted Bulgarians, so the conclusion also can be applied for Bulgarians. This work shows that the methodology of the attempted search for genetic stratification in the early 2000s did not provide the desired results and points to the need for more samples and integration with archaeology and genealogy.

The research results of another team (Olivieri et al., 2013) are rather different. The previous research of the various European mtDNA haplogroups documented that haplogroups I and W have southern European and Near Eastern components poorly represented, meaning there are extensive hidden phylogenetic substructures that remain to be uncovered. Olivieri and his colleagues reexamined the available datasets of I and W complete mtDNA genomes (a sample of 419 genomes) and searched for precise correlations between the ages and geographical distribution of their numerous newlyidentified subclades with "events of human dispersal which contributed to the genetic formation of modern Europeans." Their results showed that haplogroups I (within N1a1b) and W emerged in the Near East during the Late Glacial Maximum or prewarming period (19 ky-15 ky ago). These groups, along with the more common $\mathrm{J}$ and $\mathrm{T}$ groups, might have contributed to the postglacial repopulating of Europe (see also the discussion for Linear Band Ceramics complex in Central Europe in Hofmann, 2015; Bentley et al., 2012). 
Recently, the theme of Neanderthal inheritance has become popular because of the special DNA test kit offering (The Genographic Project, 2018).

From a theoretical point of view, the term ethnicity in genetic genealogy needs to be accepted as a synonym of geographical regions that have temporal in-depth characteristics without proving absolute chronology in all cases. For instance, the "ethnical" term "Italy, Greece" on the Ancestry.com map covers huge areas including parts of Bulgaria. Territories like contemporary Bulgaria actually belong to different ethnic zones that overlap. Similarly, the term Middle East relates to Anatolia, etc. In fact, the geographical names are technical terms that describe the most scientific results coming from the DNA analyses. Those who oppose genetic genealogy as an advanced science do not look at the core of the results but criticize the external characteristics of technical entities without analyzing their content in depth.

In the case of the Neanderthal component in the DNA of the contemporary population, genetic genealogy intersects with the results of genetic anthropology. Research showing the pros and cons of using DNA results for cultural-historical conclusions (see, e.g., Guedes et al., 2013; Torres, 2014) helps to develop a more advanced methodology to apply genetic research to social science. Genetic genealogy redefines the cultural identity of individuals and historical/ethnical and social groups and is one extremely powerful means for re-intellectualizing the human mind with scholarly objective constructs. The fact that the conclusions of DNA tests can be used for political and ideological applications neither damages the scientific image of the genetic studies nor makes DNA tests a danger to society (cp. Torres, 2014).

\subsection{Algorithm of Genetic Sequences and Other Statistical Programs}

An important component of genetic genealogy is the algorithm used for genetic sequences and comparing genetic data. The DNA testing companies do not provide information on which algorithms they use and it is unclear whether the similarity between the results of the various companies involves a component of using the same or a similar algorithm. However, learning about the current state of the scientists' efforts to find the best algorithms for genetic research helps to unveil the "secrets" of genetic genealogy in terms of the technology used.

One of the most popular works for genetic sequences is the publication by Sabaa and colleagues about the algorithm of the genome identity-by-descent determination (2013). As Tangherloni and colleagues explain, somatic "human cells are diploids, that is, they contain 22 pairs of homologous chromosomes and a pair of sex chromosomes, one copy inherited from each parent." Genome research requires reconstructing the two distinct copies of each chromosome, thereby determining the haplotypes. In the process of haplotyping, all heterozygous SNPs are assigned to "exactly one of the two chromosomes (Tangherloni et al., 2017). Haplotyping is precisely that process of inferring a full haplotype. Analyzing the full sets of SNPs is especially important for disease studies.

Tangherloni and colleagues refer to two classes of methods that exist for haplotype phasingstatistical methods and sequencing "read data, exploiting an idea similar to genome assembly."'Different algorithms have been offered in a variety of scholarly works (cp. Ding et al., 2014; Lin \&Speed, 2009; Sabaa et al., 2013;Tangherloni et al., 2017; Vallania et al., 2012)

Genetic genealogy largely depends on statistical programs used to define the similarities and differences in DNA data (e.g. Lawson \&Falush, 2012). This is especially visible when comparing the data between the different companies that process DNA tests-in particular, comparing data from AncestryDNA, 23\&Me, and FamilyTreeDNA. Some authors attempt to develop their own models for estimating the ancestry of unrelated individuals (e.g. Alexander et al., 2009). Speed and Balding (2015) developed a model through computer simulations that traces back 50 generations.

The advancement in the algorithms for comparing genetic data is one of the main determinants of accuracy in genetic genealogy.

\subsection{Genetic Genealogy and Unknown Bioparentage and Disputed Parentage}

A specific topic of integration of genetic genealogy and traditional genealogy is the research on adopted children who are searching for their biological relatives. Genetic genealogy may reveal high numerical percentage matches, but traditional genealogy will either prove or clarify the nature of the match. 
The development of unknown bioparentage and disputed parent age genetic genealogy includes different stages. The current stage (after 2012) has embraced autosomal DNA testing as promising and considers it a widely applicable method of revealing human genetic identity in relation to others.

During the last few years, this branch of genetic genealogy reported endless examples of successfully reconnecting biological relatives. Although it has limitations and delimitations, this field of knowledge is one of the main current social achievements of the applied sciences since it always basesits findings on specific cases and improvesits results with the development of both genetic genealogy and traditional genealogy.

The Global Adoptee Genealogical Project (GAGP, 2017) even offers free DNA kits for qualified candidates. Partners and sponsors of the projects are $23 \& \mathrm{Me}$ and Family Tree DNA. In addition, the American Adoption Congress organizes regular conferences (AAC, 2017).

\subsection{Genetic Genealogy and Traditional Genealogy}

Genetic genealogy has become an integral component of traditional genealogy. It has two main functions: as a method for discovering relatives (e.g. adoption cases) or as a complement to traditional genealogy. The development of genetic genealogy stimulates the development of some branches of traditional genealogy. For instance, an increase in samples of Middle Eastern origin formembers of the Balkan population have an impact on those interested in the genealogy of the Ottoman Empire (Hart, 2004). The success of DNA testing in adoption also stimulates historical research on adoption (e.g. Herman, 2009). Some studies question the results of genetic genealogy referring exclusively to traditional genealogy (TallBear, 2013).

\subsection{Genetic Genealogy and Genetic Anthropology}

Currently, there are two branches of the complex science of human origins with partially overlapping subjects of research-genetic genealogy and genetic anthropology. Genetic genealogy studies the DNA of the contemporary population, while genetic anthropology is a branch of biological anthropology that studies ancient DNA (mostly from tooth and bone samples). Both branches have their own record base, but they overlap since genetic genealogy needs retrospective diachronic analyses and includes the problem of admixture DNA (ancient ethnicity), while genetic anthropology needs prospective diachronic analysis to trace migrations, ethnical changes, and human interactions at different levels. The problems of genetic anthropology intersect in many cases with physical anthropology and other social sciences (e.g. Tostevin, 2007).

Genetic genealogy has a diverse function in traditional genealogy. In some cases, DNA results may support the conclusions of traditional genealogy based on indirect evidence or when developed as a hypothesis backed by exclusively negative arguments (absence of evidence) (see, e.g., Fox, 2011; Pratt, 2012; Mills, 2014; Akaha\&Unkefer, 2015). In other cases, genetic genealogy and traditional genealogy may have an equal role in the analyses and conclusions. The third type of research encompasses genetic studies, which use traditional genealogy to support or clarify the results of the DNA analyses (e.g. the adoption cases). The last type is an example of the necessary integration of genetic genealogy and traditional genealogy. In cases of optimal integration, the genetic results expand the knowledge of the ancestry and may bring to light completely new ideas. For instance, some Bulgarians have $6 \%$ or more British origin, a result that raises a variety of hypotheses.

In many cases, however, genetic genealogy cannot help to resolve basic research questions since it has many limitations.

\subsection{Genetic Genealogy and Museums}

One innovative tendency is to develop genealogical centers in museums, including DNA test interpretations. A pioneer in this movement is the International African American Museum (IAAM, 2017) in Charleston, South Carolina. Thanks to its website, the center began to function even before the opening of the museum's exposition.

\subsection{Genetic Genealogy, Law, and Ethics}

Numerous publications discuss the interrelation of using DNA tests in genealogy. The ethical issues have been summarized by Bettinger (2016, 35-48). Among the most critical topics are unexpected 
DNA results like false parenting. Ethical issues need to be implemented in every module of the curricula instead of in only one independent module. In other words, instead of traditionally discussing ethics and subject, the ethical approach can become part of the methodology of the curricula.

\subsection{Academic Curriculum and Emerging Knowledge and Technologies}

Genetic genealogy is an example of emerging knowledge using emerging technologies. The patterns of emerging fields of knowledge are not yet established and their target is the innovative but irreversible spiral of progression. Accordingly, in such cases the academic curriculum attempts not only to communicate innovation, but also to create a learning environment of patterning the subjects taught, thereby stimulating progression.

In their monograph on the theory of curriculum, Wiggins and McTighe (2012: 3) state that "a curriculum works with the standards to frame optimal learning experiences." However, in cases of emerging knowledge, the curriculum not only provides the template for lifelong learning experiences, but also functions as a means of transforming innovations into standards.

In the early $21^{\text {st }}$ century, the general methodology and theory of the academic curriculum is constructivism. In many fields of academic knowledge - genetic studies, in particular-the constructivism is paired with culturally responsive teaching (Jabbar and Hardaker, 2013). Teaching genetic studies also has the peculiarity of requiring instructors to combine idea-based learning with their own methodologies (Hansen, 2006), and using quantitative raw data and statistical and simulation methods of research and learning.

In addition, advancements in project-based learning; effective visualization of the teaching and presenting of the research results of students; development of the methodology of strategizing goals, objectives, and steps of learning; and persistent actualization of the framework of the curriculum create a foundation for sustainable teaching, lifelong learning, and achievements.

\section{DisCUSSION AND CONCLUSION}

The literature review provided on the curricula and other learning resources for genetic genealogy attempted to answer the questions listed at the beginning of the chapter in order to elucidate with evidence why the development of a curriculum for a genetic genealogy course is an actual scholarly task.

As the review shows, there is no real academic curriculum for genetic genealogy. The existing curricula have a primarily social function to assist researchers of family history to understand the results of DNA tests. The curricula follow the contemporary level of genetic genealogy research from the perspective of family history, especially by expanding the curriculum with more detailed analysis of auDNA applications. Current curricula do not embrace the whole problem of genetic genealogy, which population genetics research partially covers. Typically, population genetics studies embed emerging technology and innovations to develop a highly effective academic curriculum, although the changes happen very slowly and do not include the whole framework of the curricula. A serious gap was documented in the population genetics curricula for doctoral students - the absence of a solid program for the archaeological study of human origin. This may explain the fact that many maps of genetic origin in fact replicate old archaeological maps and conclusions of archaeologists that are outdated in some cases. The impression is that the geneticists' raw data create a basis for different interpretations, and the conclusions of the archaeologists are taken as a template for modeling the raw data. However, since doctoral candidate geneticists do not have a solid program for the archaeological study of origin, they often uncritically replicate archaeological maps in their conclusions. A recommendation for including a solid program for archaeological study of human origin is one of the important results of this review The same is equally important for integrating genetic genealogy and population genetics by increasing the geneticists' requirement to learn the fundamentals of general genealogy, just as genetic genealogists should learn the fundamentals of population genetics. This research also recommends that ethical problems be covered in all modules by developing an ethical approach as part of the methodology of the curricula.

The research of the literature shows that genetic genealogy has become an integrative component of traditional genealogy and its place in traditional genealogy gradually increases. 
The absence of a developed academic curriculum for genetic genealogy also means that the current curricula with applied focus on personal family history are missing some of the main requirements of academic curricula, including conducting a rapid needs assessment, selecting innovative assessment strategies, and refining learning experiences. However, they have clearly defined rationales, goals, and objectives. Their teaching strategy relies mainly on traditional lectures while assessment is through testing. Teaching genetic genealogy today can feature much more variable effective teaching strategies, with developed curricula for discussion and project-based assessments and learning strategies.

The review of the literature for curricula and resources for genetic genealogy learning infer that a complete academic curriculum for genetic genealogy is missing in the scholarly sources currently available. Such a curriculum would fill a considerable gap in the contemporary complex science of human origin and civilizations, serving the academic needs not only of genetic genealogy, but also of historians, geneticists, sociologists, family historians, cultural anthropologists with interests in genealogy, and those in other disciplines that intersect with genetic genealogy.

\section{ACKNOWLEDGMENTS}

I would like to thank my chair dissertation, Dr. Kerrie Naylor - Argosy University, Salt Lake City, Utah, USA, for her thoughtful guidance while working on the applied dissertation on-going project. My gratitude is extended to Ms. Danamichele Brennen, the General Manager of AncestryProGenealogists, Salt Lake City, Utah, USA, for the opportunity to have an internship in Genetic Genealogy at AncestryProGenealogists.

Several collegues from the same company assisted me in advancing in my expertise on theoretical genetic genealogy - Mr. Michael Miller, Mr. Nathan Machula, Ms. Kathryn Moore and Ms. Angie Bush. I would like also to thank them and all other colleagues from the company whose meaningful answers to my questions and assistance in the learning process contributed to buiding a background for my current scholarly achievements.

\section{REFERENCES}

[1] Websites of the most popular applied genetic genealogy companies:

[2] AncestryDNAhttp://www.ancestry.com

[3] FamilyTreeDNAhttp://www.familytreedna.com

[4] 23\&Me http://www.23andme.com

[5] AAC (2017). American Adoption Congress. Retrieved from https://www.americanadoptioncongress.org/

[6] Akaha, J.,\&Unkefer, R. (2015).Is a Rabbi hiding in your family tree? Lessons from genetic genealogy for traditional genealogists. Avotaynu, 31(3), 15-21.

[7] Alexander, D. H., Novembre, J., \&Lange, K. (2009). Fast model-based estimation of ancestry in unrelated individuals. Genome Research,19, 1655-1664.

[8] Andrews, R.M., Kubacka, I., Chinnery, P.F., Lightowlers, R.N., Turnbull, D.M.,\&Howell, N. (1999). Reanalysis and revision of the Cambridge reference sequence for human mitochondrial DNA. National Genetics, 23(2), 147. DOI: 10.1038/13779

[9] Behar, D. M., van Oven, M. Rosset, S., Metspalu, M., Loogväli, E.-L., Silva, N. M., Kivisild, T., ...\&Villems, R. (2012). A “Copernican”' reassessment of the human mitochondrial DNA tree from its root. The American Journal of Human Genetics, 90, 675-684.

[10] Bentley, R. A., Bickle, P., Fibigerc, L., Nowelld, G. M.,Daled, C. W., Hedgesc, R. E. M.,...\&Whittle, A. (2012).Community differentiation and kinship among Europe's first farmers. Proceedings of the National Academy of Sciences of the United States of America, 109(24), 9326-9330.

[11] Bergfeld, A. K., Lawrencea, R., Diaza, S. L., Pearcea, O. M. T., Ghaderia, D., Gagneuxa, P. , ... \&Varkia, A. (2017).N-glycolyl groups of nonhuman chondroitin sulfates survive in ancient fossils. Proceedings of the National Academy of Sciences of the United States of America, 114(39). Doi:10 1073/pnas.1706306114. Retrieved from http://www.pnas.org.

[12] Bettinger. B. T. (2016). The Family Tree guide to DNA testing and genetic genealogy. Cincinnati, OH: Family Tree Books.

[13] Bettinger, B. T. (2018). Genetic genealogist. Retrieved from https://thegeneticgenealogist.com/

[14] Bettinger, B. T.,\&Wayne, D. P. (2016). Genetic genealogy in practice. USA: National Genealogical Society. 
[15] Bosch, E., Calafell, F., Gonzalez-Neira, A., Flaiz, C., Mateu, E., Scheil, H.-G., ...\&Comas, D. (2006). Paternal and maternal lineages in the Balkans show a homogeneous landscape over linguistic barriers, except for the isolated Aromuns. Annals of Human Genetics, 70, 459-487.

[16] Cassidy, L. M., Martiniano, R., Murphy, E. M., Teasdale, M. D., Mallory, J., Hartwell, B.,\&Bradley, D. G. (2016). Neolithic and Bronze Age migration to Ireland and establishment of the insular Atlantic genome. Proceedings of the National Academy of Sciences of the United States of America, 113(2), 368-373. https://doi.org/10.1073/pnas.1518445113.

[17] Cheesman, K., French, D., Cheesman, I., Swails, N., \&Thomas, J. (2007). Is there any common curriculum for undergraduate biology majors in the $21^{\text {st }}$ century? BioScience, 57(6), 516-522.

[18] Coursera (2017). Retrieved from http://www.coursera.com

[19] Courses for success (2018). Certificate in genealogy basics online course. coursesforsuccess.com. Retrieved from https://www.coursesforsuccess.com.au

[20] Danchin, E., Pujol, B.,\& Wagner, R. H. (2013). The double pedigree: A method for studying culturally and genetically inherited behavior in tandem. Plos One, 20 May 2013. Retrieved from https://doi.org/10.1371/ journal.pone.0061254.

[21] Dawson, V., Carson, K., \&Venville, G. (2010). Genetics curriculum materials for the 21st century. The Journal of the Australian Science Teachers Association, 56(4), 38-42.

[22] Ding, X., Gu, H., Zhang, Z., Li, M., \&Wu, F. (2014). Searching SNP combinations related to evolutionary information of human populations on HapMap Data. In: M. Basu, Y. Pan, \&J. Wang (Eds), Bioinformatics research and applications. ISBRA 2014. Lecture Notes in Computer Science, 8492.

[23] ENCODE (2018). Encyclopedia of DNA elements. encodeproject.org. Retrieved from https://www.encodeproject.org

[24] Evison, M. P. (2003). Archaeology and DNA. C.J.C. Reuvenslezing-15. Amsterdam: Stichtingvoor de NederlandseArcheologie. ISBN 9076289077

[25] Evison, M. P. (2014). Genetics, archaeology, and culture. Mediterranean Archaeology and Archaeometry, 14(1), 301-319.

[26] Fox, J. K. (2011). Documents and DNA identify a little-known Lee family in Virginia. National Genealogical Society Quaterly, 99, 85-96.

[27] GAGP (2017). Global Adoptee Genealogical Project. Retrieved from http://discovergagp.org/apply-freedna-test-kit/

[28] Genetic Genealogy 101 (2018). Home study course. Retrieved from https://www.familytreemagazine.com

[29] Genetic Genealogy Resources (2018). isogg.org. Retrieved from https://isogg.org

[30] Guedes, J. d'A., Bestor, T. C., Carrasco, D., Flad, R., Fosse, E., Herzfeld, M., Lamberg-Karlowsky, C. C.,... \&Warinner, C.(2013). Is poverty in our genes? Current Anthropology, 54(1), 71-79.

[31] Haak, W., Lazaridis, I., Patterson, N., Rohland, N., Mallick, S., Llamas, B., ...\&Reich, D. (2015). Massive migration from the steppe was a source for Indo-European languages in Europe. Nature, 522, 207-211. doi: 10.1038/ nature14317.

[32] Hamilton, M. (2009). Population genetics. Hoboken, NJ: John Willey \& Sons Ltd.

[33] Hansen, E. J. (2006). Idea-based learning. A course design process to promote conceptual understanding. Sterling, VA: Stylus Publishing.

[34] Hart, A. (2004). Searching genealogy records in the former Ottoman empire. archive.org. Retrieved from https://archive.org

[35] Hein, J., Schierup, M. H., \&Wiuf, C. (2004). Gene genealogies, variation and evolution: A primer in coalescent theory. Oxford: Oxford University Press.

[36] Herman, E. (2008). Kinship by design: A history of adoption in the modern United States. Chicago, Ill: The University of Chicago Press.

[37] Herrera, R. J., Garcia-Bertrand, R.,\&Salzano, F. M. (2016). Genomes, evolution, and culture: Past, present, and future of humankind. West Sussex, UK: John Wiley \& Sons Inc.

[38] Hoban, S., Bertorelle, G., \&Gaggiotti, O. E. (2012). Computer simulations: tools for population and evolutionary genetics. Nature, 13, 110-122.

[39] Hofmann, D. (2015). What Have Genetics Ever Done for Us? The Implications of aDNA Data for Interpreting Identity in Early Neolithic Central Europe. European Journal of Archaeology, 18(3), 454476.

[40] IAAM (2017). International African American Museum. cfh.iaamuseum.org. Retrieved from https://cfh.iaamuseum.org/marriage-records/ 
[41] Indiana State Library (2006). Genealogy Resources for K-12 Educators. Indiana State Library, Genealogy Division. USA: Indiana State Library.

[42] International Society of Genetic Genealogy Wiki (2018). Beginners' guides to genetic genealogy. Retrieved from https://isogg.org

[43] Jabbar, A., \&Hardaker, G. (2013). The role of culturally responsive teaching for supporting ethnic diversity in British University Business Schools. Teaching in Higher Education, 2013, 1-13. doi:10.1080/13562517.2012.725221.

[44] Jones, T. W. (2007). Postsecondary study of genealogy: curriculum and its contexts. Avotaynu online, 1 October 2007. Retrieved from http://www.avotaynuonline.com

[45] Klein, G. (2015). Resisting cancer. The Scientist, April 2015. Retrieved from http://www.the-scientist.com

[46] Kliman, R. M. (2001). A project-based approach to teaching complex population genetics to undergraduates. Bioscene, 27(4), 13-20.

[47] Kovalchuk, I.,\&Kovalchuk, O. (2010). Genome instability and transgenerational effects.

[48] New York, NY: Nova Science Publishers, Inc.

[49] Kridel, C. A. (Ed.) (2010). Encyclopedia of curriculum studies. Thousand Oaks, CA: Sage.

[50] Larmuseau, M. H. D., Van Geystelen, A., van Oven, M.,\&Decorte, R. (2013). Genetic genealogy comes of age: Perspectives on the use of deep-rooted pedigrees in human population genetics. American Journal of Physical Anthropology, 00, 1-7.

[51] Lawson, D. J.,\&Falush, D. (2012). Population identification using genetic data. Annual Review of Genomics and Human Genetics, 13, 337-361.

[52] Lin, S.,\&Speed, T. P. (2009). An algorithm for haplotype analysis. Journal of Computational Biology, 4(4), 535-546. https://doi.org/10.1089/cmb.1997.4.535

[53] McAllister, B. (2016). Who are you? Revelations from The Personal Genome. Course Schedule. Retrieved from https://wiki.uiowa.edu

[54] McElhinny, T. L., Dougherty, M. J., Bowling, B. V., \&Libarkin, J. C. (2014). The status of genetic curriculum in higher education in the United States: Goals and assessment. Science and Education, 23, 445-464.

[55] Meloni, M. (2014). The social brain meets the reactive genome: neuroscience, epigenetics and the new social biology. Frontiers in Human Neuroscience, 8, 21 May 2014. doi: 10.3389/fnhum.2014.00309. Retrieved from https://www.ncbi.nlm.nih.gov

[56] Mills, E. S. (2014). Testing the FAN principle against DNA: Zilphy (Watts) Price Cooksey Cooksey of Georgia and Mississippi. National Genealogical Society Quarterly, 102, 129-152.

[57] Mostafavi, H., Berisa, T., Day, F. R., Perry, J. R. B., Przeworski, M., \&Pickrell, J. K. (2017). Identifying genetic variants that affect viability in large cohorts. PLoS Biology, 15(9): e2002458. Retrieved from http://journals.plos.org.

[58] Murray-Nseula, M. (2011). Incorporating case studies into an undergraduate genetics course. Journal of the Scholarship of Teaching \& Learning, 11(3), 75-85.

[59] National Center for Case Study Teaching in Science (2017). Case collection. National Center for Case Study Teaching in Science. Retrieved from http://sciencecases.lib.buffalo.edu/cs/collection/

[60] National Genealogical Society (2017a). Genetic genealogy, the basics. Continuing genealogical studies. National Genealogical Society. Retrieved from https://www.ngsgenealogy.org

[61] National Genealogical Society (2017b). Genetic genealogy. Autosomal DNA. Continuing genealogical studies. National Genealogical Society. Retrieved from https://www.ngsgenealogy.org

[62] National Science Foundation (2017). Award Abstract \#1533613. Personalized genetics and genealogy exercises to enhance introductory biology courses. National Science Foundation. Retrieved from https://www.nsf.gov

[63] NCBI (n.d.). NCBI Reference Sequence: NC_012920.1. Retrieved from https://www.ncbi.nlm.nih.gov

[64] NCSU (2017). GN703: Population and quantitative genetics. Spring 2017. Syllabus and schedule. Retrieved from https://brcwebportal.cos.ncsu.edu

[65] Nikolova, L. (1999). The Balkans in Later Prehistory. Oxford: BAR.

[66] Nikolova, L. (2018). Scholarly branches in 21st-century genealogy (Earliest 19th-century Bulgarian immigrants in the US at ancestry.com). Journal of Historical Archaeology \& Anthropological Sciences, $1(6), 1-10$.

[67] Olivieri, A., Pala, M., Gandini, F., Kashani, B. H., Perego, U. A., Scott, R., ... \&Torroni, A. (2013). Mitogenomes from two uncommon haplogroups mark late Glacial/Postglacial expansions from the Near 
East and Neolithic dispersals within Europe. Plos One, 8(7), 1-12.

[68] Online Courses (2018). Retrieved from https://www.ngsgenealogy.org

[69] PBS (2017). Finding your roots with Henry Louis Gates Jr. pbs.org. Retrieved from http://www.pbs.org

[70] Pratt, W. C. (2012). Finding the father of Henry Pratt of Southeastern Kentucky. National Genealogical Society Quarterly, 100, 85-103.

[71] Sabaa, H., Cai. Z., Wang, Y., Goebel, R., Moore, S., \&Lin, G. (2013). Whole genome identity-by-descent determination. Journal of Bioinformatics and Computational Biology, 11(2). doi: 10.1142/S0219720013500029

[72] Speed, D., \& Balding, D. J. (2015). Relatedness in the post-genomic era. Nature Reviews Genetics, 16, 33 34.

[73] TallBear, K. (2013). Native American DNA. Minneapolis, MN: The University of Minnesota Press.

[74] Tangherloni, A., Spolaor, S., Rundo, L., Nobile, M. S., Merelli, I., .. \& Pietro, L. (2017). GenHap: A novel computational method based on genetic algorithms for haplotype assembly. PeerJPrePrints; San Diego (Sep 12, 2017).

[75] Taylor, R. M., \&Crandall, R. J. (1986). Generations and change: Genealogical perspectives in social history. Macon, GA: Mercer University Press.

[76] The Encode Project Consortium (2012). An integrated encyclopedia of DNA elements in the human genome. Nature, 489(7414), 57-74. Retrieved from https://www.ncbi.nlm.nih.gov

[77] The Genographic Project (2018). The human story. The National Geographic. Revealed from https://genographic.nationalgeographic.com/

[78] Torres, J. B. (2014). Prospecting the past: genetic perspectives on the extinction and survival of indigenous peoples of the Caribbean. New Genetics and Society, 9 Jan 2014. DOI: 10.1080/14636778.2013.873245. Retrieved from http://www.tandfonline.com

[79] Tostevin, G. (2007). Social Intimacy, Artefact Visibility, and Acculturation Models of NeanderthalModern Human Interaction. In P. Mellars, K. Boyle, O. Bar-Yosef and C. Stringer (Eds.), Rethinking the human revolution (pp. 341-357). Cambridge, UK: McDonald Institute for Archaeological Research, University of Cambridge.

[80] UK Biobank (2015). Genotype imputation and genetic association studies of UK Biobank. Interim Data Release. Retrieved from http://www.ukbiobank.ac.uk

[81] UNC (2017). Curriculum in Genetics and Molecular Biology. The University of North Carolina at Chapel Hill. Retrieved from http://gmb.unc.edu

[82] Understanding Evolution (n.d.). berekely.edu. Retrieved from https://evolution.berkeley.edu

[83] Vallania, F., Ramos, E., Cresci, S., Mitra, D. R., and Druley, T. E. (2012). Detection of Rare Genomic Variants from Pooled Sequencing Using SPLINTER. Journal of Visualized Experiments, 64. Retrieved from https://www.ncbi.nlm.nih.gov

[84] Wheaton Surname Resources (2013). Beginners guide to genetic genealogy. Retrieved from https://sites.google.com

[85] Wiggins, G., \&McTighe, J. (2012). Understanding by design guide to advanced concepts in creating and reviewing units. Alexandria, VA: ASCD.

\section{AUTHOR'S BIOGRAPHY}

Dr. Lolita Nikolova, Genealogist Researcher at Ancestry Proenealogists and Research Professor at Internatinal Institute of Anthropology, Salt Lake City, Utah, USA is a world-wide published author and leading global anthropologist-scientist today. Her field of research includes prehistory of Eurasia, theory of prehistory, social and cultural anthropology, law anthropology, anthropology of everydayness, semiotics of culture, traditional genealogy, theoretical genetic genealogy, etc. Her monograph "The Balkans in Later Prehistory" (1999) is a classic piece of scholarly insights into the development of the Balkans during the fourth and third millennia cal BCE. In the last decade, most popular is her article on the interrelation between watching pornography and domestic violence (2011). Most recently, she published a classification of genealogy as a complex social discipline (2017). In print is her scholarly work on the gold during the Early Bronze Age in Eurasia, following a presentation at ASOR (2017).

Nikolova's anthropological interest in changing parameters of the cultural identity in the $21^{\text {st }}$ century has brought her in the field of genetic genealogy. She has been working on an applied dissertation project to develop a curriculum of genetic genealogy within EdD program at Argosy University. Her 
Genetic Genealogy as an Emerging Research Branch of Human Ancestry and Origin (Review of Curricula and Other Learning Sources)

online course "Introduction to Cultural Genomics" (yescourse.com, 2018) is part of the first in the world specialization in Cultural Genomics.

Most of her scholarly works are available at amazon.com, academia.edu and Research Gate. Website: http://www.iianthropology.org

Citation: Lolita Nikolova. "Genetic Genealogy as an Emerging Research Branch of Human Ancestry and Origin (Review of Curricula and Other Learning Sources)" International Journal of Humanities, Social Sciences and Education (IJHSSE), vol 5, no. 3, 2018, pp. 169-183. doi: http://dx.doi.org/10. 20 431/ 23490381.0503018.

Copyright: (C) 2018 Authors. This is an open-access article distributed under the terms of the Creative Commons Attribution License, which permits unrestricted use, distribution, and reproduction in any medium, provided the original author and source are credited. 